\title{
Anodização porosa de nióbio com adição de glicerina
}

\author{
Niobium porous anodizing with \\ glycerin addition
}

\author{
Aline Silveira Barreto ${ }^{1}$, Luciane Thaís Fuhr ${ }^{1}$, \\ Leonardo Felix Scheffel ${ }^{1}$, Fernando Dal Pont Morisso', \\ Carlos Leonardo Pandolfo Carone ${ }^{1}$, Sandra Raquel Kunst ${ }^{2}$, \\ Jane Zoppas Ferreira ${ }^{2}$, Cláudia Trindade Oliveira ${ }^{1}$
}

\footnotetext{
${ }^{1}$ ICCT, Universidade Feevale, RS-239, 2755, Novo Hamburgo, RS, Brasil.

${ }^{2}$ LACOR, Federal Universidade do Rio Grande do Sul - UFRGS, Avenida Bento Gonçalves, 9500, Porto Alegre, RS, Brasil.

e-mail: alinebarreto84@gmail.com, luciane.fuhr@gmail.com, scheffel1234@gmail.com, morisso@feevale.br, carloscarone@feevale.br, tessaro.sandra@gmail.com,jane.zoppas@ufrgs.br, cto@feevale.br
}

\begin{abstract}
RESUMO
O nióbio é um metal que forma óxido aderente e protetor em contato com o ar, possuindo a propriedade de se autoproteger. O método utilizado para acelerar o crescimento do óxido é conhecido como anodização, no qual o óxido formado pode ser do tipo barreira ou poroso. O óxido poroso é amplamente estudado e pode ser utilizado em células solares, sensores de gás, como biomaterial, entre outros. No entanto, óxidos porosos em nióbio têm sido obtidos com uso de $\mathrm{F}^{-}$, o que provoca intenso processo de dissolução do óxido. Com intuito de minimizar essa reação, eletrólitos contendo glicerina tem favorecido o processo de anodização formando superfícies porosas uniformes. Nesse sentido, o objetivo deste trabalho é obter estruturas nanoporosas em nióbio por anodização a partir de parâmetros conhecidos. A partir de $\left(12,73 \mathrm{~mA} . \mathrm{cm}^{-2}, 100 \mathrm{~V}\right)$, tempos $(5$ e 30 minutos), concentração de HF (2,24\%) e uso de cátodo de platina, já utilizados em estudo anterior, foi inicialmente testada a influência do cátodo de aço inoxidável em substituição à platina, visando promover uma futura transferência tecnológica. A partir disso, a fim de minimizar o processo de dissolução que ocorreu com o uso de HF (2,24\%), apenas a HF (1\%) foi testada. Finalmente, para obter uma estrutura de óxido mais uniforme, adicionou-se glicerina ao eletrólito de HF (1\%). O uso do cátodo de aço inoxidável, apesar de influenciar os resultados dos transientes de anodização, devido a sua provável dissolução química, mostrou-se eficaz no processo. Amostras anodizadas com menores concentrações de HF e com adição de glicerina, como esperado, apresentaram menor dissolução durante a formação dos óxidos, originando estruturas nanoporosas, além de microcones.
\end{abstract}

Palavras-chave: Nióbio; Anodização; Glicerina; Óxido poroso.

\begin{abstract}
Niobium is a metal that forms adherent protective oxide in contact with the air, which has the property of self-protection. The method used to accelerate the growth of the oxide is known as anodizing, in which the oxide formed may be barrier or porous. Porous oxide is widely studied and can be used in solar cells, gas sensors, as biomaterial, among others. However, porous oxides in niobium have been obtained with the use of F-, which causes an intense dissolution process of the oxide. In order to minimize this reaction, electrolytes containing glycerine have favored the anodizing process forming uniform porous surfaces. In this sense, the objective of this study is to obtain nanoporous structures in niobium by anodization from known parameters. From $\left(12.73 \mathrm{~mA} . \mathrm{cm}^{-2}, 100 \mathrm{~V}\right)$, times (5 and 30 minutes), HF concentration $(2.24 \%)$ and platinum cathode use, already used in a previous study, was initially tested the influence of the cathode of stainless steel in substitution to the platinum, aiming to promote a future technological transference. From this, in order to minimize the dissolution process that occurred using HF (2.24\%), only HF (1\%) was tested. Finally, in order to obtain a more uniform oxide structure, glycerin was added to the HF electrolyte (1\%). The use of the stainless steel cathode, although influencing the results of the anodizing transients, due to its probable chemical dissolution, proved effective in the process. Anodized samples with lower concentrations of HF and with
\end{abstract}


addition of glycerine, as expected, presented lower oxide dissolution during oxide formation, originating nanoporous structures, besides microcones.

Keywords: Niobium; Anodization; Glycerin;.Porous oxide

\section{INTRODUÇÃO}

O crescimento da demanda por matérias primas mais eficientes está colocando os chamados "minerais raros" ou "estratégicos" em evidência. No topo da lista destes minerais estão o nióbio e seus óxidos, os quais têm sido formados por meio do processo de anodização. Este processo possibilita a obtenção de óxidos nanoporosos e com isso, aumenta a possibilidade de aplicações tecnológicas, tais como uso em sensores de gás, matrizes catalíticas e catalisadores [1,2], em dispositivos ópticos e eletrocrômicos [3,4,5], células solares [6,7], em baterias de lítio [8], dentre outros. Entre as vantagens do nióbio podem-se citar a alta resistência à corrosão e estabilidade termodinâmica [11].

Segundo Zhao et al. [12], Carniti et al. [13], Mujawar et al. [14], Jose et al. [15], Ahn et al. [16], dentre os óxidos de nióbio, o $\mathrm{Nb}_{2} \mathrm{O}_{5}$ é o material mais conhecido e estudado. Ele apresenta propriedade de semicondutor com um band gap de cerca de 3,4 eV [18,19]. Na oxidação anódica a tensão aplicada entre os eletrodos cria um campo eletrostático no óxido e faz com que os íons de nióbio e de oxigênio migrem através do filme pré-existente para então reagirem e formarem o óxido. A reação pode acontecer no interior do óxido e/ou na interface óxido-eletrólito [20]. Através do processo de anodização, o óxido formado é atacado quimicamente pelo eletrólito, resultando na formação de poros da ordem de nanômetros, os quais podem apresentar forma de nanotubos e nanofibras, por exemplo [21].

Os eletrólitos mais utilizados, atualmente, para realização desse processo contém HF em sua formulação, que, apesar de ser um ácido fraco, é altamente corrosivo e é capaz de dissolver muitos materiais, inclusive óxidos. Dessa forma, é necessário controle do processo a fim de evitar que o íon fluoreto cause a total dissolução do óxido no momento da anodização [22,23]. Esse controle é realizado a partir de ajustes em alguns parâmetros do processo, como potencial aplicado, densidade da corrente e tempo de anodização. De acordo com Kowalski [24], a adição de HF é fundamental para a formação de estruturas nanoporosas em metais que formam óxidos protetores ao ar, tais como titânio, tungstênio e nióbio, com exceção do alumínio, e dependendo das condições de anodização, é possível a obtenção de camadas de óxido [25].

Portanto, o objetivo deste trabalho é obter estruturas nanoporosas em nióbio por anodização a partir de parâmetros conhecidos. A partir de $\left(12,73 \mathrm{~mA} \cdot \mathrm{cm}^{-2}, 100 \mathrm{~V}\right)$, tempos $(5$ e 30 minutos), concentração de HF $(2,24 \%)$ e uso de cátodo de platina, já utilizados em estudo anterior, foi inicialmente testada a influência do cátodo de aço inoxidável em substituição à platina, visando promover uma futura transferência tecnológica.

\section{MATERIAIS E MÉTODOS}

\subsection{Preparação das amostras}

O nióbio puro (99,8 \%), utilizado nas anodizações, foi fornecido pela Companhia Brasileira de Metalurgia e Mineração (CBMM), na forma de chapa, com $100 \mu \mathrm{m}$ de espessura. A partir desta chapa de nióbio, foram cortadas amostras nas dimensões de $1,5 \times 1,5 \mathrm{~cm}$, com área total anodizada de $2,25 \mathrm{~cm}^{2}$. Essas foram lixadas e polidas, até acabamento espelhado. Após, as amostras foram decapadas durante 10 segundos em solução $40 \% \mathrm{HF}+60 \% \mathrm{HNO}_{3}$. Após a decapagem as amostras foram enxaguadas em água deionizada e secas com ar frio.

\subsection{Anodização e caracterização das amostras}

As anodizações foram feitas com aplicação de $12,73 \mathrm{~mA} \cdot \mathrm{cm}^{-2}$ e $100 \mathrm{~V}$ a temperatura ambiente por 5 e $30 \mathrm{mi}-$ nutos. O processo iniciou em modo galvanostático com aplicação de $12,73 \mathrm{~mA} . \mathrm{cm}^{-2}$, com monitoramento do potencial. Depois que o potencial atingiu $100 \mathrm{~V}$ o processo passou a ser potenciostático com monitoramento da densidade de corrente. Neste caso, o aumento de espessura do óxido está limitado pelo potencial aplicado, e o óxido funciona como uma resistência dificultando a passagem de corrente elétrica [26]. O eletrólito de anodização foi uma solução de 0,3 mol.L $\mathrm{L}^{-1}$ de ácido oxálico, com adições de $2,24 \%$ e $1 \%$ HF, e $1 \%$ em volume de glicerina. A nomenclatura adotada para as amostras conforme condições de anodização está mostrada na Tabela 1. 
Tabela 1: Nomenclatura das amostras conforme condições de anodização.

\begin{tabular}{|c|c|}
\hline Amostra & Condições de anodização \\
\hline AO-5 & 0,3 mol.L $\mathrm{L}^{-1}$ Ácido Oxálico - 5 minutos \\
\hline $\mathrm{AO}-30$ & 0,3 mol.L $\mathrm{L}^{-1}$ Ácido Oxálico - 30 minutos \\
\hline AOHF2,24-5 & 0,3 mol.L L $^{-1}$ Ácido Oxálico + 2,24 \% v/v HF - 5 minutos \\
\hline AOHF2,24-30 & 0,3 mol. $\mathrm{L}^{-1}$ Ácido Oxálico + 2,24 \% v/v HF - 30 minutos \\
\hline AOHF1-5 & 0,3 mol.L -1 $^{-1}$ cido Oxálico + $1 \%$ v/v HF - 5 minutos \\
\hline AOHF1-30 & 0,3 mol.L $\mathrm{L}^{-1}$ Ácido Oxálico + $1 \%$ v/v HF - 30 minutos \\
\hline AOHF1GLIC1-5 & 0,3 mol.L $\mathrm{L}^{-1}$ Ácido Oxálico + $1 \% \mathrm{v} / \mathrm{v} \mathrm{HF}+1 \% \mathrm{v} / \mathrm{v}$ glicerina -5 minutos \\
\hline AOHF1GLIC1-30 & 0,3 mol. $\mathrm{L}^{-1}$ Ácido Oxálico $+1 \% \mathrm{v} / \mathrm{v} \mathrm{HF}+1 \% \mathrm{v} / \mathrm{v}$ glicerina -30 minutos \\
\hline
\end{tabular}

O equipamento utilizado para as anodizações foi uma fonte de potencial x corrente (300 V x $500 \mathrm{~mA})$ acoplado a um computador com software para aquisição de dados. As amostras foram anodizadas em triplicata e verificadas quanto à morfologia e quanto à espessura por meio de microscopia eletrônica de varredura. Para tanto, foi utilizado o equipamento Microscópio Eletrônico de Varredura, marca Jeol, modelo JSM6510LV. As amostras foram analisadas em vista de topo e seção transversal.

\section{RESULTADOS E DISCUSSÃO}

\subsection{Transientes de anodização}

Na Figura 1 são mostrados os transientes de (a) e (b) densidade de corrente e (c) e d) potencial das amostras anodizadas em 0,3 mol. $\mathrm{L}^{-1}$ ácido oxálico, com e sem adição de HF e glicerina, por 5 e 30 minutos. Para melhor entendimento dos transientes, as letras (a) e (c) da fígura 1 são uma ampliação das curvas até 300s e as letras (b) e (d) mostram os transientes até 1800 segundos. Observa-se que as curvas mostram um aumento linear do potencial com o tempo enquanto a corrente permanece constante. Depois disso, o potencial atinge o valor máximo de $100 \mathrm{~V}$ e a corrente diminui. Este comportamento é típico de crescimento de óxidos por anodização. No entanto, o comportamento das curvas difere de acordo com a adição de HF ao eletrólito de ácido. Isto provocou oscilações na densidade de corrente e no potencial, o que foi relacionado à dissolução do óxido, e à formação de poros em função do $\mathrm{F}^{-}$[28].
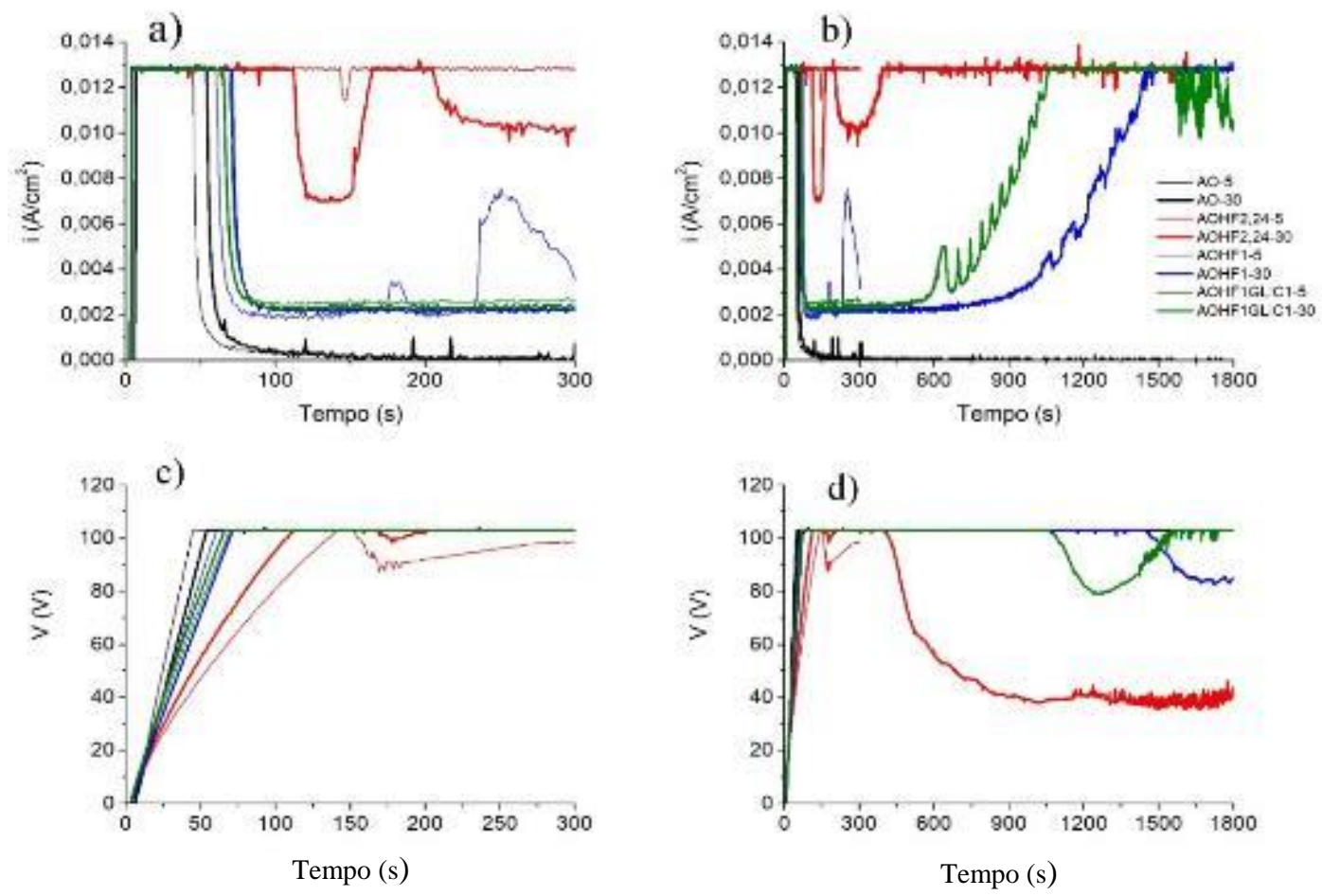

Figura 1: Transientes de densidade de corrente a) 300s e b) 1800s e transientes de potencial c) 300s e d) 1800s de nióbio anodizado em 0,3 mol. $L^{-1}$ ácido oxálico com adição de HF e glicerina. 
O aumento linear do potencial, no início do processo de anodização, até $100 \mathrm{~V}$, gera uma constante $(\partial V / \partial t)$ chamada de taxa de anodização ou taxa de crescimento e seus valores são apresentados na Tabela 2 , onde é apresentada a média das condições de anodização, bem como o desvio padrão.

Tabela 2: Taxas de crescimento das amostras anodizadas.

\begin{tabular}{lll}
\hline AMOSTRA & $\partial V / \partial t$ MÉDIA & DESVIO PADR ÃO \\
\hline AO-5 & 2,63 & 0,282 \\
AO-30 & 2,14 & 0,462 \\
AOHF2,24-5 & 0,72 & 0,115 \\
AOHF2,24-30 & 0,93 & 0,255 \\
AOHF1-5 & 1,82 & 0,173 \\
AOHF1-30 & 1,51 & 0,234 \\
AOHF1GLIC1-5 & 1,53 & 0,071 \\
AOHF1GLIC1-30 & 1,62 & 0,093 \\
\hline
\end{tabular}

\subsubsection{Análise dos transientes das amostras anodizadas em 0,3 mol. $\mathrm{L}^{-1}$ ácido oxálico}

Observa-se que as amostras anodizadas somente em ácido oxálico apresentam uma taxa de anodização de 2,63 (AO-5) e 2,14 V/s (AO-30), até o potencial atingir $100 \mathrm{~V}$. Comportamento semelhante já foi observado por outros autores [20]. Esse aumento linear era esperado, pois a tensão obtida durante o processo de anodização está diretamente relacionada com o crescimento do óxido [25]. Depois de atingir $100 \mathrm{~V}$, o potencial se torna constante e a densidade de corrente diminui, chegando a praticamente zero, indicando comportamento típico da formação de óxido barreira em que a passagem da corrente é dificultada pelo crescimento de óxido [25].

Bianchin e pesquisadores [26] verificaram que a taxa de crescimento de óxidos formados nas mesmas con-dições usando cátodo de platina foi 1,32 vezes maior $(3,47 \mathrm{~V} / \mathrm{s})$ do que as amostras deste trabalho, o que pode estar associado a menor eficiência catódica do aço inoxidável em comparação à platina, devido à película protetora do aço inoxidável formada espontaneamente ao ar [27]. Durante a anodização da amostra AO30, após o potencial estabilizar em $100 \mathrm{~V}$ e a densidade de corrente diminuir, observou-se a formação de uma película escura na superfície do aço inoxidável. A figura 2 mostra a vista de topo do cátodo de aço inoxidável contendo duas interfaces, em que uma delas trata-se da a) região do cátodo não imersa na solução de anodização e a b) região do cátodo imersa na solução de anodização.

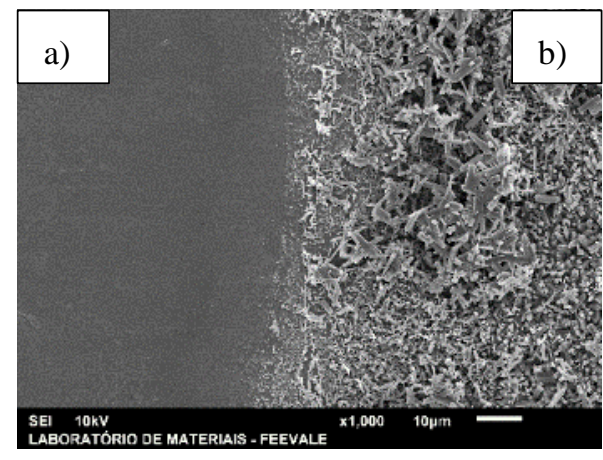

Figura 2: Micrografia de topo do cátodo de aço inoxidável contendo duas interfaces, em que uma delas trata-se da a) região do cátodo não imersa na solução de anodização e a b) região do cátodo imersa na solução de anodização.

Na figura 2 identifica-se a formação de produto de corrosão na parte imersa em solução de ácido oxálico. Neste caso, com a diminuição da densidade de corrente, a solução de ácido oxálico passa a agir direta- 
mente no cátodo formando o produto de corrosão e no ânodo, por meio da dissolução, o que explicaria a obtenção de superfície porosa nesta amostra (AO-30).

\subsubsection{Análise dos transientes das amostras anodizadas em 0,3 mol.L ${ }^{-1}$ ácido oxálico + 2,24 \% HF}

A adição de 2,24 \% HF ao eletrólito de ácido oxálico fez com que as amostras anodizadas (AO-5, AO-30, AOHF224-5, AOHF224-30, AOHF1-5, AOHF1-30, AOHF1GLIC1-5, AOHF1GLIC1-30) apresentassem taxa de crescimento semelhante, porém menos linear do que aquelas anodizadas somente em ácido oxálico (AO-5, AO-30). No entanto, após cerca de 100 segundos, estas amostras apresentaram diminuição do potencial, com posterior oscilação até, aproximadamente, 300 segundos, atingindo em torno de $40 \mathrm{~V}$ ao final do processo de anodização (1800 segundos). Isto, provavelmente, ocorreu devido à alta concentração de HF na solução eletrolítica, o que provocou a dissolução do óxido e a formação de poros. Como a intensidade de formação nesse óxido foi maior do que aquele formado sem a presença de HF, o que ficou evidenciado pela densidade de corrente medida, supõem-se que esse comportamento seja devido à migração do íon fluoreto através do óxido, formando uma camada porosa [24]. Esse comportamento não foi verificado por Bianchin [26] na anodização feita com cátodo de platina, em que o potencial se manteve constante até $100 \mathrm{~V}$. Além disso, as amostras anodizadas com cátodo de platina apresentaram potencial 3,27 vezes maior (2,36 V/s) do que as anodizadas com cátodo de aço inoxidável, o que pode estar associado à dissolução química do cátodo de aço inoxidável no eletrólito contendo HF.

Nas amostras anodizadas em 2,24\% HF, os transientes de densidade de corrente apresentaram comportamento semelhante, com valor constante até o potencial atingir $100 \mathrm{~V}$. Depois disso ocorreram oscilações da densidade de corrente, até 300 segundos, no valor de 12 a $7 \mathrm{~mA} . \mathrm{cm}^{-2}$, atingindo valor aproximado de 13 mA.cm ${ }^{-2}$ ao final do processo (1800 segundos). Bianchin et al. [26] também observaram comportamento semelhante em seus estudos, em que a densidade de corrente obtida até 300 segundos foi de $3,82 \mathrm{~mA} . \mathrm{cm}^{-2}$, chegando a 12,10 mA.cm ${ }^{-2}$ em 1800 segundos. Os autores descrevem a formação da camada barreira (com a diminuição da densidade de corrente) e o subsequente crescimento da camada exterior nanoporosa (com aumento da densidade de corrente) e sua estabilização. Porém, nos experimentos realizados por Bianchin et al. [26] não se observaram oscilações da densidade de corrente, o que pode estar relacionado à elevada quantidade de HF no meio, fazendo com que o óxido apresente comportamento irregular devido à formação da camada porosa.

\subsubsection{Análise dos transientes das amostras anodizadas $0,3 \mathrm{~mol}^{-1} \mathrm{~L}^{-1}$ ácido oxálico $+1 \% \mathrm{HF}$}

Observa-se que as amostras anodizadas em menor concentração de HF também apresentaram crescimento linear do potencial, 1,82 (AOHF1-5) a 1,5 V/s (AOHF1-30), e densidade de corrente constante até o potencial atingir $100 \mathrm{~V}$. Nota-se que a taxa de crescimento é aproximadamente 2 vezes maior do que aquela obtida em 2,24 \% HF. Isto indica a formação de um óxido com menor taxa de dissolução. Depois disso, ocorre uma diminuição da corrente até aproximadamente $2 \mathrm{~mA} \cdot \mathrm{cm}^{-2}$. A partir daí, é possível observar uma oscilação na densidade de corrente da amostra anodizada em 300 segundos, enquanto a amostra anodizada em 1800 segundos permanece constante até aproximadamente 1000 segundos, quando ocorre um aumento quase linear desta, até atingir novamente $12 \mathrm{~mA} . \mathrm{cm}^{-2}$. Esse comportamento é devido ao eletrólito que contém HF em sua composição. Isso causa oscilações na densidade de corrente, pois o ácido penetra nos poros causando a diminuição da resistividade do óxido. Esse mesmo comportamento foi observado na amostra contendo 2,24 \% $\mathrm{HF}$, porém com maior intensidade, o que já era esperado, uma vez que a quantidade de HF é maior. Nota-se que a diminuição da concentração de HF no eletrólito de anodização ainda provoca intensa dissolução no óxido, o que foi observado com as oscilações e aumento da densidade de corrente ao longo do processo.

\subsubsection{Análise dos transientes das amostras anodizadas em $0,3 \mathrm{~mol} . \mathrm{L}^{-1}$ ácido oxálico $+1 \% \mathrm{HF}+1 \% \mathrm{v} / \mathrm{v}$ glicerina}

As amostras anodizadas com adição de $1 \% \mathrm{v} / \mathrm{v}$ glicerina apresentaram comportamento semelhante às que não continham esta substância. A taxa de anodização parece não ter sido influenciada pela adição de glicerina, 1,53 (AOHF1GLIC1-5) e 1,62 V/s (AOHF1GLIC1-30). Não se observou oscilação da densidade de corrente até 300 segundos. No entanto, o aumento quase linear da corrente ocorreu em um tempo de 600 segundos, (AOHF1GLIC1-30), menor em comparação ao da amostra de $1 \%$ HF que foi de 1000 segundos, (AOHF130). Isto indica que a glicerina pode não ter evitado a formação da camada porosa. 


\subsection{ANÁLISE MORFOLÓGICA DAS AMOSTRAS ANODIZADAS}

\subsubsection{Morfologia das amostras anodizadas em 0,3 mol. $\mathrm{L}^{-1}$ ácido oxálico.}

A Figura 3 mostra as micrografias ao MEV das amostras anodizadas em ácido oxálico, em $100 \mathrm{~V}$ por 5 e 30 minutos. Observa-se que a amostra anodizada em 5 minutos (Figura 3-a) apresenta uma superfície homogênea, encobrindo as concavidades oriundas do processo de decapagem. Isto indica a formação de óxido do tipo barreira. Já a amostra anodizada em 30 minutos (Figura 3-c) apresenta poros na superfície, indicando um provável processo de dissolução, o que não era esperado, uma vez que a densidade de corrente final foi praticamente nula para esta condição de anodização. Esse comportamento não foi observado por Bianchin et al. [26], que obteve morfologia homogênea, sem poros, nestas condições de anodização, porém utilizando cátodo de platina. A única diferença observada entre o processo utilizado por Bianchin et al. [26] e o processo mostrado neste trabalho é o uso de cátodo de aço inoxidável ao invés da platina, que poderia ser o responsável pela formação dos poros.

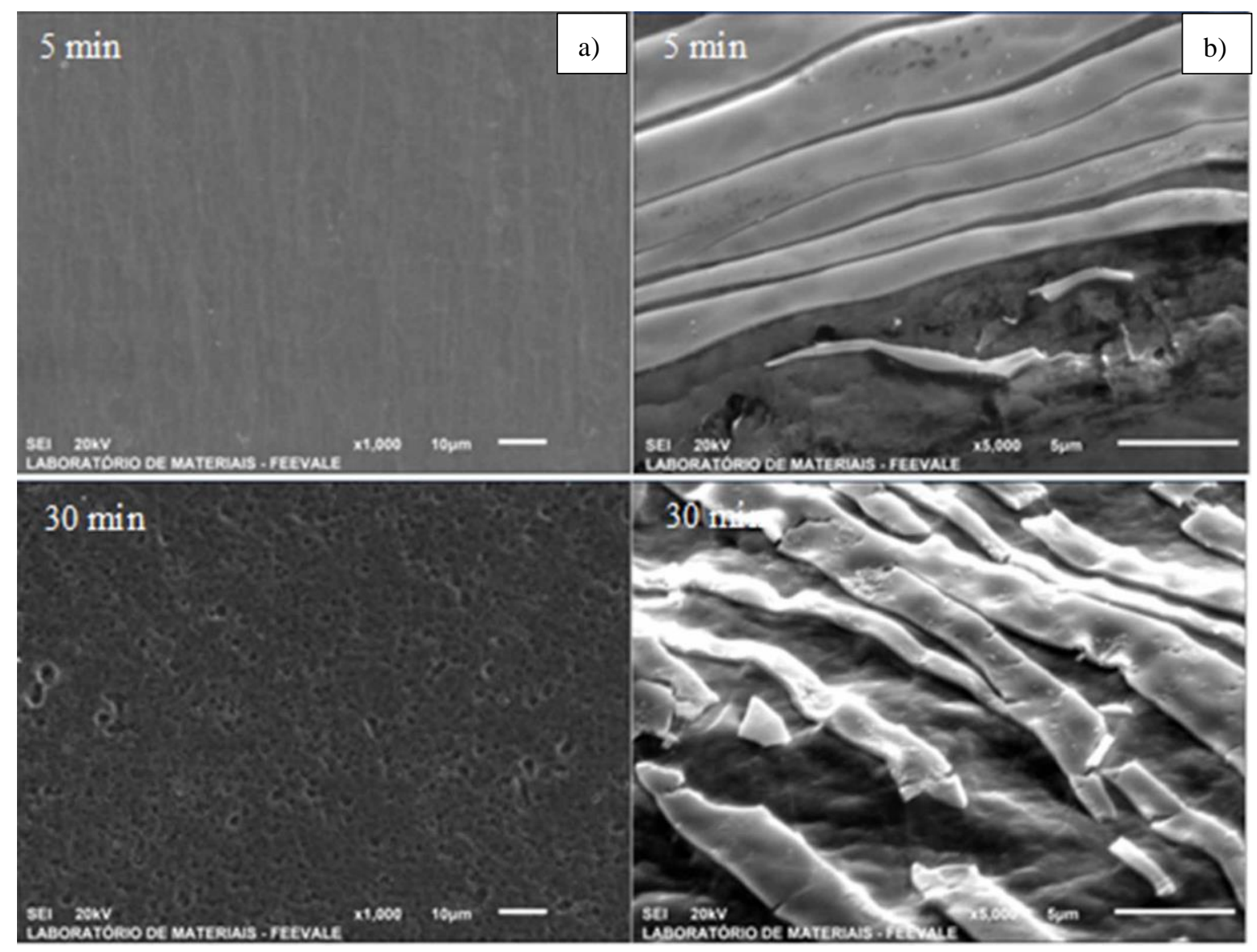

Figura 3: Micrografias com vistas de topo e seção transversal das amostras anodizadas em 0,3 mol.L ${ }^{-1}$ ácido oxálico, $12,73 \mathrm{~mA} . \mathrm{cm}^{-2}, 100 \mathrm{~V}$, em 5 min. (a e b) e 30 min. (c e d).

\subsubsection{Morfologia das amostras anodizadas em 0,3 mol. $\mathrm{L}^{-1}$ ácido oxálico + 2,24 \% HF}

A Figura 4 mostra o nióbio anodizado em ácido oxálico com 2,24 \% HF nos tempos de 5 e 30 minutos. Observa-se que a amostra anodizada em 5 minutos apresenta poros, os quais parecem ocorrer ao longo das concavidades esféricas, obtidas devido ao processo de decapagem. Isso indica o início da formação de óxido poroso, decorrente do eletrólito. De acordo com Choi et al. [4], esse comportamento ocorre devido ao tempo de anodização elevado (12 horas), em que parte da camada de óxido é completamente dissolvida, resultando em uma estrutura não-planar. No entanto, na amostra mostrada neste trabalho, o tempo de anodização foi de 5 minutos, o que não concorda com o exposto pelo autor Bianchin et al. [26] que também obteve estrutura porosa, anodizando nas mesmas condições deste trabalho, porém com cátodo de platina. Além disso, este resultado está de acordo com a densidade de corrente observada por Bianchin et al., na qual ocorreram osci- 
lações, em que a densidade de corrente final atinge $12 \mathrm{~mA} \cdot \mathrm{cm}^{-2}$.

$\mathrm{Na}$ amostra anodizada em 30 minutos, a dissolução foi mais intensa, devido ao tempo de processo, e houve a formação de camadas descontínuas de óxido e microcones. Este evento pode ser atribuído à dissolução provocada pelo HF, caracterizando a dissolução da camada porosa e início da formação de nova camada de óxido. Este comportamento foi da mesma forma conferido por Bianchin et al. [26], que após observar estas formações simultâneas entre óxidos barreiras e óxidos porosos, propôs um modelo de formação de óxido de acordo com o tempo de anodização. O modelo descreve o crescimento de camadas descontínuas e microcones, sendo que os dois tipos de formações foram observados nas micrografias da amostra anodizada em $2,24 \% \mathrm{HF}$, no tempo de 30 minutos.

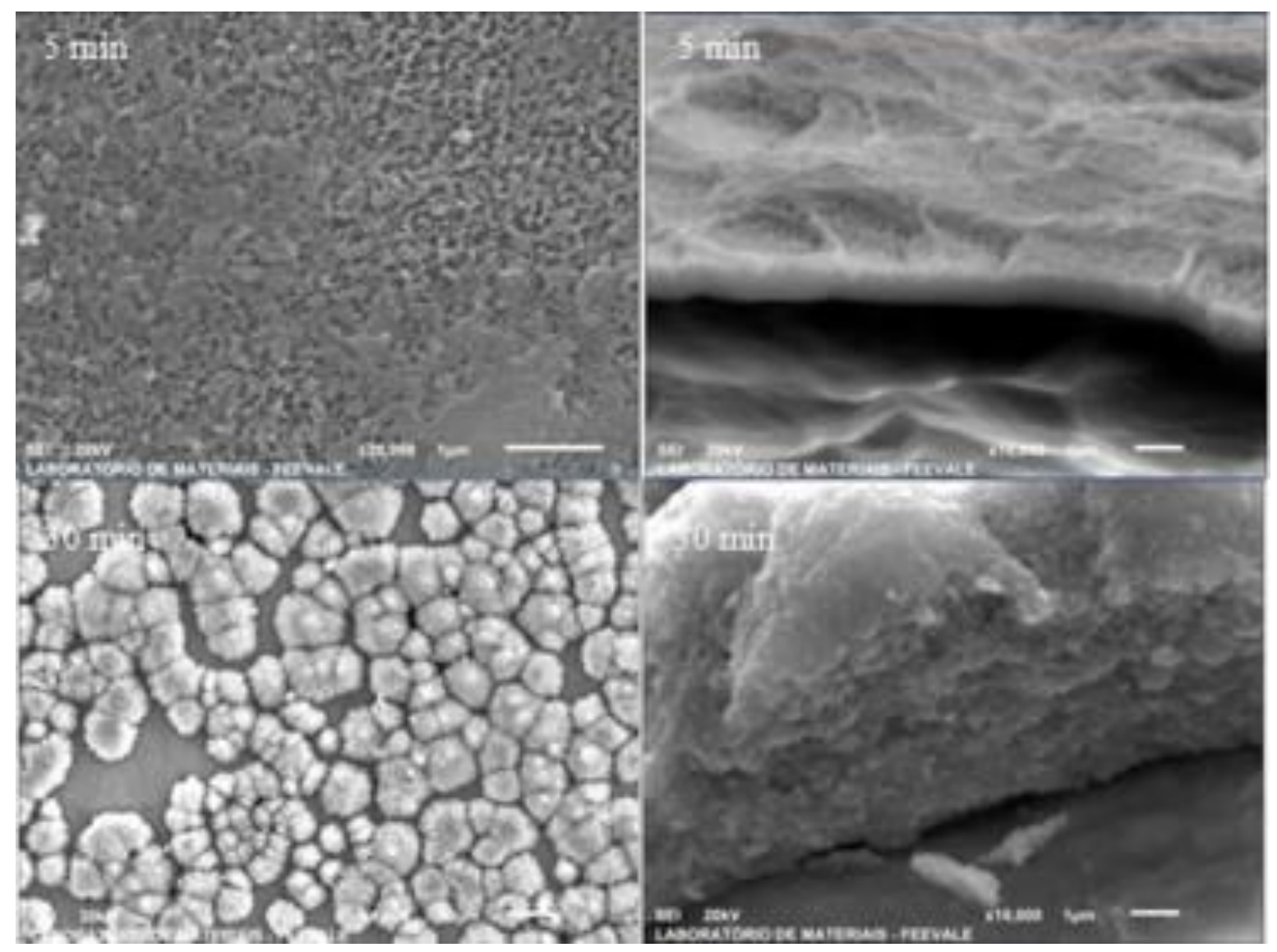

Figura 4: Micrografias com vistas de topo e seção transversal das amostras anodizadas em 0,3 mol.L $\mathrm{L}^{-1}$ ácido oxálico + $2,24 \% \mathrm{HF}, 12,73 \mathrm{~mA} \cdot \mathrm{cm}^{-2}, 100 \mathrm{~V}$, em 5 e $30 \mathrm{~min}$.

\subsubsection{Morfologia das amostras anodizadas em 0,3 mol. $\mathrm{L}^{-1}$ ácido oxálico + $1 \% \mathrm{HF}$}

Na Figura 5 são apresentadas as micrografias das amostras de nióbio anodizadas em ácido oxálico com $1 \%$ HF por 5 e 30 minutos. Na amostra anodizada por 5 minutos observa-se a formação de poros na superfície, com protuberâncias crescendo na base do óxido. De acordo com Bianchin et al. [26], em seu modelo ocorre a formação de protuberâncias decorrentes da formação de óxido cristalino. Tanto nesta quanto na amostra anodizada por 30 minutos, nota-se a formação de poros bem mais definidos do que aqueles formados em 2,24\% HF, indicando a menor dissolução provocada neste eletrólito, o que já era esperado com a diminuição da quantidade de HF. O aumento do tempo de anodização provoca maior dissolução no óxido, com formação de cones e camadas descontínuas. 

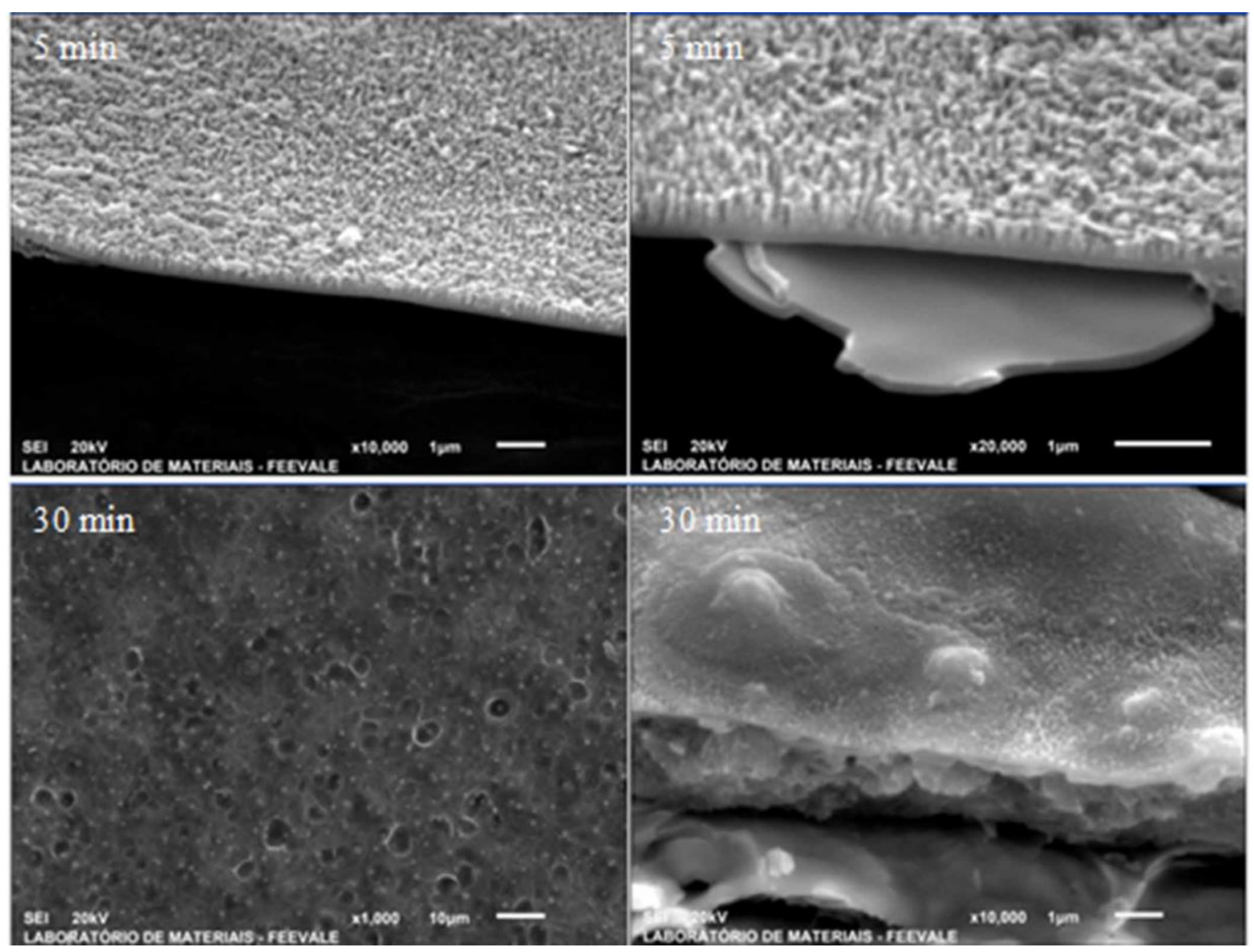

Figura 5: Micrografias com vistas de topo e seção transversal das amostras anodizadas em 0,3 mol. $\mathrm{L}^{-1}$ ácido oxálico + 1 $\%$ HF, 12,73 mA.cm ${ }^{-2}, 100 \mathrm{~V}$, em 5 e 30 minutos.

\subsubsection{Morfologia das amostras anodizadas em $0,3 \mathrm{~mol}^{\mathrm{L}} \mathrm{L}^{-1}$ ácido oxálico $+1 \% \mathrm{HF}+1 \%$ glicerina}

Na Figura 6 são apresentadas as micrografias das amostras anodizadas em ácido oxálico com $1 \%$ de $\mathrm{HF}$ e com adição de $1 \%$ de glicerina, nos tempos de 5 e 30 minutos. Apesar do eletrólito apresentar HF em sua composição, observa-se a formação de camada porosa, porém não se observa diferença na morfologia com relação às amostras anodizadas sem a adição da glicerina. Da mesma forma, Bervian et al. [28], em sua publicação, mencionam que na anodização de aço inoxidável em eletrólito $\mathrm{H}_{2} \mathrm{SO}_{4}$ o processo de dissolução foi menos intenso com a adição de glicerina, e explica isto devido à diminuição da condutividade do eletrólito, reduzindo o processo de dissolução e a formação de poros. Wu et al. [29] obteve revestimento cerâmico em magnésio fundido AZ91D pelo processo de MAO (Micro-arc Oxidation) em eletrólito contendo glicerina e silicato. Os autores observaram que a adição de glicerina ao eletrólito melhorou o desempenho do revestimento cerâmico, com a obtenção de menos poros e microfissuras. Os poros da amostra obtido a partir do eletrólito livre de glicerina apresentou um diâmetro de $8,5 \mathrm{~nm}$. O diâmetro da amostra obtida com $4 \mathrm{~mL} . \mathrm{L}^{-1}$ de glicerina foi de 2,63 $\mathrm{nm}$. A adição de glicerina no eletrólito de silicato aumentou a capacidade de unidade de área de adsorção de íons negativos na molécula de silicato, melhorando a capacidade e a resistência a corrosão do revestimento de MAO, e consequentemente diminuindo a quantidade de íons $\mathrm{F}^{-}$livres para dissolução e formação e poros. 

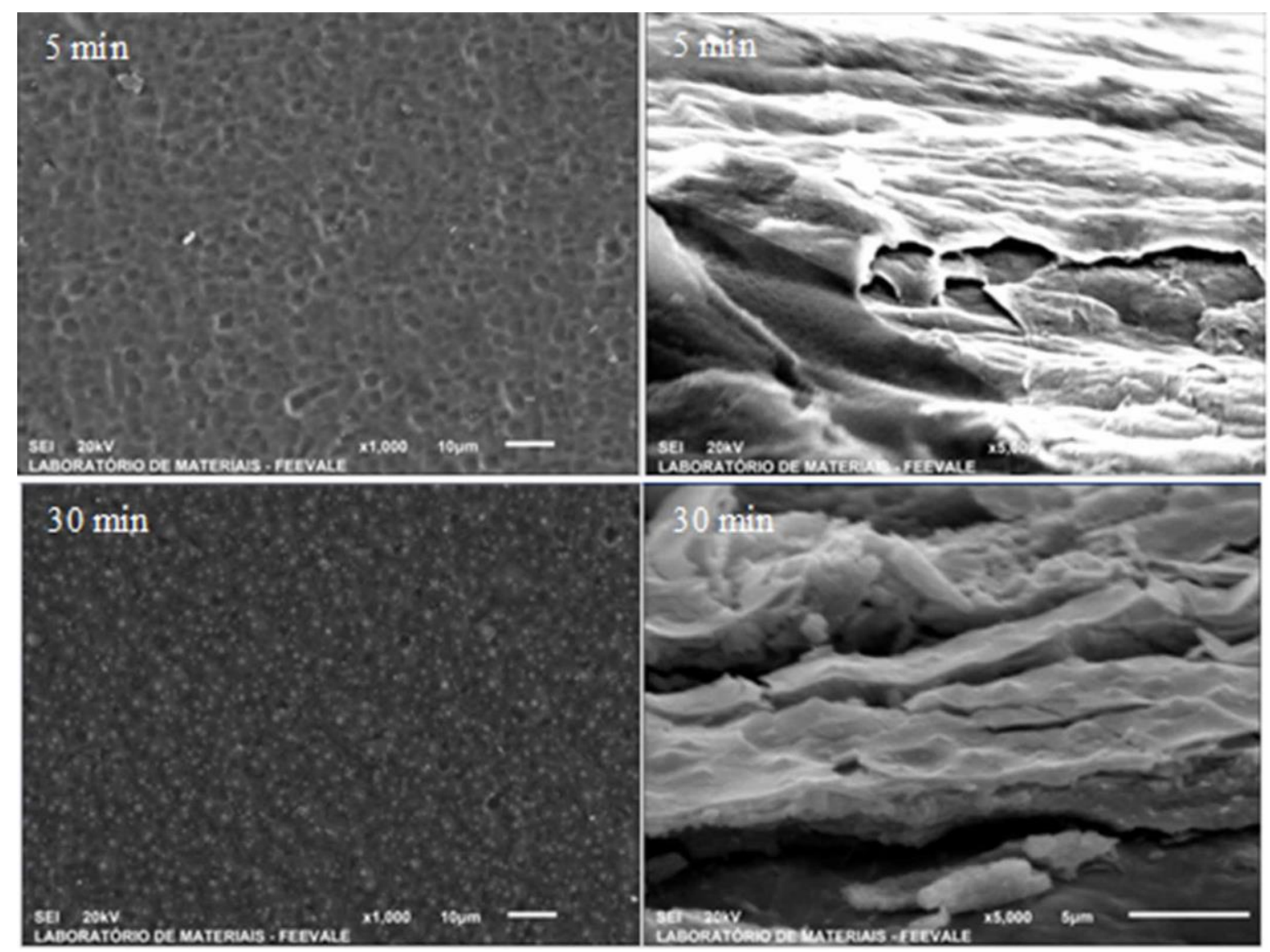

Figura 6: Micrografias com vistas de topo e seção transversal das amostras anodizadas em 0,3 mol. $\mathrm{L}^{-1}$ ácido oxálico + 1 $\% \mathrm{HF}+1 \%$ glicerina, $12,73 \mathrm{~mA} \cdot \mathrm{cm}^{-2}, 100 \mathrm{~V}$, em 5 e $30 \mathrm{~min}$.

\section{CONCLUSÃO}

O presente trabalho apresentou os resultados de anodização das amostras de nióbio puro, em eletrólitos à base de ácido oxálico com adições de ácido fluorídrico e glicerina. A partir deste estudo, foi possível testar a influência da adição de ácido fluorídrico em diferentes concentrações, identificando que a diminuição da concentração de ácido fluorídrico favorece a formação de estruturas porosas mais ordenadas, com menor dissolução. A adição de glicerina diminuiu o processo de dissolução, porém, embora tenha havido formação de camada porosa, não foi verificado diferença morfológica com relação à amostra sem glicerina. Quanto ao uso do cátodo de aço inoxidável, apesar de ter ocorrido formação de produto de corrosão em sua superfície, influenciando os resultados das anodizações, observa-se que é possível e viável, industrialmente, o uso deste material.

\section{AGRADECIMENTOS}

Os autores gostariam de expressar sua gratidão à ajuda financeira da CAPES e do CNPq. A CBMM pela disponibilização do Nióbio.

\section{BIBLIOGRAFIA}

[1] ALVES, A.R., COUTINHO, A.R. "The Evolution of the Niobium Production in Brazil", Materials Research, v.18, pp.106-112, 2015.

[2] TANABE, K. "Catalytic application of niobium compounds", Catalysis Today, v.78, pp.65-77, 2003.

[3] TSUCHIYA H., SCHMUKI P., "Thick self-organized porous zirconium oxide formed in H2SO4/NH4F electrolytes", Electrochemistry Communications, v.6, pp.1131-1134, 2004.

[4] CHOI J., LIM J.H., LEE S.C., et al., "Porous niobium oxide films prepared by anodization in $\mathrm{HF} / \mathrm{H}_{3} \mathrm{PO}_{4}$ ", Electrochimica Acta, v.51, pp.5502-5507, 2006. 
[5] TZVETKOV, B., BOJINOV, M., GIRGINOV, A., et al., "An electrochemical and surface analytical study of the formation of nanoporous oxides on niobium", Electrochimica Acta, v.52, pp.7724-7731, 2007.

[6] RANI, R.A., ZOOLFAKAR, A.S., OU J.Z., et al., "Nanoporous $\mathrm{Nb}_{2} \mathrm{O}_{5}$ hydrogen gas sensor", Sensors and Actuators B, v.176, pp.149-156, 2013.

[7] RANI, R.A., ZOOLFAKAR, A.S., SUBBIAH, J., et al., "Highly ordered anodized $\mathrm{Nb}_{2} \mathrm{O}_{5}$ nanochannels for dye-sensitized solar cells", Electrochemistry Communications, v.40, pp.20-23, 2014.

[8] YOO, J.E., PARK J., CHA, G., CHOI J, "Micro-length anodic porous niobium oxide for lithium-ion thin film battery applications", Thin Solid Films, v.531, pp.583-587, 2013.

[9] SU, Z., ZHOU, W., "Porous Anodic Metal Oxides”, Science Foundation in China, pp. 16-36, 2008.

[10] BAUER, S., PARK, J., VON DE MARK, K., et al., "Improved attachment of mesenchymal stem cells on super-hydrophobic $\mathrm{TiO}_{2}$ nanotubes”, Acta Biomaterialia, v. 4, pp. 1576-1580, 2008.

[11] KARLINSEY, R.L., "Preparation of self-organized niobium oxide microstructures via potentiostatic anodization", Electrochemistry communications, v. 7, pp. 1190-1194, 2005.

[12] ZHAO, Y., ZHOU, X., Ye, L., et al., "Nanostructured $\mathrm{Nb}_{2} \mathrm{O}_{5}$ catalysts”, Nano Reviews, v. 3, 2012.

[13] CARNITTI, P., GERVASINI, A., MARZO, M., "Dispersed NbOx catalytic phases in silica matrixes: influence of niobium concentration and preparative route", The Journal Physical Chemical C, v. 112, pp. 14064-14074, 2008.

[14] MUJAWAR, S.H., INAMDAR, A.I., PATIL, S.B., et al., "Electrochromic properties of spray-deposited niobium oxide thin films", Solid State Ionics, v. 177, pp. 3333-3338, 2006.

[15] JOSE, R., THAVASI, V., RAMAKRISHNA, S. "Metal oxides for dyesensitized solar cells", Journal of The American Ceramic Society, v. 92, p. 289, 2009.

[16] AHN, K.S., KANG, M.S., LEE, J.K., et al., "Enhanced electron diffusion lenght of mesoporous $\mathrm{TiO}_{2}$ film by using $\mathrm{Nb}_{2} \mathrm{O}_{5}$ energy barrier for dye-sensitized solar cells", Applied Physics Letters, v. 89, pp.013103, 2006.

[17] JEONG, B.Y., JUNG, E.H., KIM, J., "Fabrication of superhydrophobic niobium pentoxide thin films by anodization”, Applied Surface Science, v. 307, pp. 28-32, 2014.

[18] ZHAO, Y., ZHOU, X., Ye, L., et al., "Nanostructured $\mathrm{Nb}_{2} \mathrm{O}_{5}$ catalysts”, Nano Reviews, v. 3, 2012.

[19] WU, J., LI, J., LU, X., et al., “A one-post method to grow pyrocholore $\mathrm{H}_{4} \mathrm{Nb}_{2} \mathrm{O}_{7}$-octahedron-based photocatalyst", Journal of Master Chemistry, v.20, pp.1942-6, 2010.

[20] CERNIAK, S.N., GOMES, U.U., "Efeito do tempo de patamar e temperatura na sinterização do nióbio para aplicação em capacitores eletrolíticos de nióbio", In: anais do VI Congresso Nacional de Engenharia Mecânica, Paraíba, 2010.

[21] BONATTO, Fernando, "Síntese e caracterização de nanoestruturas formadas pela anodização de titânio", Dissertação de mestrado do programa de pós graduação em Ciência dos Materiais, Universidade Federal do Rio Grande do Sul, Porto Alegre, 2009.

[22] YOO, J.E., PARK J., CHA, G., CHOI J., "Micro-length anodic porous niobium oxide for lithium-ion thin film battery applications", Thin Solid Films, v. 531, pp. 583-587, 2013.

[23] OIKAWA, Y., MINAMI, T., MAYAMA, H., et al., "Preparation of self-organized porous anodic niobium oxide microcones and their surface wettability", Acta Materials, v. 57, pp. 3941-3946, 2009.

[24] KOWALSKI D., KIM D., SCHMUKI P., "TiO 2 nanotubes, nanochannels and mesosponge: Selforganized formation and applications", Nanotoday, v. 8, pp. 235-264, 2013.

[25] OLIVEIRA, C. T., "Caracterização microestrutural e eletroquímica de óxidos de Nb crescidos por anodização", Tese de D.Sc., Metalurgia e Materiais da UFRGS, 2007.

[26] BIANCHIN, A.C.V., MALDANER, G.R., FUHR, L.T., et al., “A Model for the Formation of Niobium Structures by anodization", Materials Research, v.20, pp.1010-1023, 2017.

[27] XUEHAN W. , ZHILE Y. , ZHENG W., et al., "The influence of copper on the stress corrosion cracking of 304 stainless steel”, Applied Surface Science, v. 478, pp. 492-498, 2019.

[28] BERVIAN, A., LUDWIG, G.A., KUNST, S.R., et al., "The influence of the glycerin concentration on the porous structure of ferritic stainless steel obtained by anodization", DYNA (Medellín), v. 82, pp. 46-52, 2015. 
[29] WU, D., LIU, X., LU, K., et al., "Influence of $\mathrm{C}_{3} \mathrm{H}_{8} \mathrm{O}_{3}$ in the electrolyte on characteristics and corrosion resistance of the microarc oxidation coatings formed on AZ91D magnesium alloy surface", Applied Surface Science, v. 255 p. 7115-7120, 2009.

\section{ORCID}

Aline Silveira Barreto

https://orcid.org/0000-0001-9578-0553

Luciane Thaís Fuhr

https://orcid.org/0000-0001-8053-3613

Leonardo Felix Scheffel

https://orcid.org/0000-0002-3502-7225

Fernando Dal Pont Morisso

https://orcid.org/0000-0002-9653-9857

Carlos Leonardo Pandolfo Carone

https://orcid.org/0000-0002-4084-4502

Sandra Raquel Kunst

http://orcid.org/0000-0002-8060-3981

Jane Zoppas Ferreira

http://orcid.org/0000-0002-3137-297X

Cláudia Trindade Oliveira

https://orcid.org/0000-0002-4472-5359 